\title{
Carotid Intima-Media Thickness in Asymptomatic Subjects With Low Lipoprotein(a) Levels
}

\author{
Kazuhiko Kotani ${ }^{\mathrm{a}, \mathrm{b}, \mathrm{c}}$, Naoki Sakane ${ }^{\mathrm{a}}$
}

\begin{abstract}
Background: Elevated and extreme circulating levels of lipoprotein(a) ( $\mathrm{Lp}(\mathrm{a}))$ are considered to be an atherosclerotic risk factor, although additional studies on the low levels of $\mathrm{Lp}(\mathrm{a})$ are necessary to provide confirmation. The carotid intima-media thickness (CIMT) is known as a surrogate index of atherosclerosis. The aim of the present study was to investigate the correlation between the serum Lp(a) and CIMT in asymptomatic subjects with a relatively low $\mathrm{Lp}(\mathrm{a})$ level.
\end{abstract}

Methods: The study included 65 asymptomatic female Japanese subjects (mean age: 60 years) with a serum $\mathrm{Lp}$ (a) level $<30 \mathrm{mg} / \mathrm{dL}$. Clinical data including the serum Lp(a) and CIMT were measured, and their correlations were examined.

Results: The median $\mathrm{Lp}$ (a) level was $18.6 \mathrm{mg} / \mathrm{dL}$ and the mean CIMT level was $0.8 \mathrm{~mm}$. There was a significant and inverse correlation between the CIMT and $\mathrm{Lp}(\mathrm{a})(\mathrm{r}=-0.24, \mathrm{P} \leq 0.05)$, in addition to a significant and positive correlation between the CIMT and subject age and systolic blood pressure. A stepwise multiple linear regression analysis identified the $\mathrm{Lp}(\mathrm{a})$ to be correlated indepen-

Manuscript accepted for publication March 7, 2012

${ }^{\mathrm{a}}$ Division of Preventive Medicine, Clinical Research Institute, National Hospital Organization Kyoto Medical Center, Kyoto, Japan

${ }^{\mathrm{b}}$ Department of Clinical Laboratory Medicine, Jichi Medical

University, Tochigi, Japan

${ }^{\mathrm{c}}$ Corresponding author: Kazuhiko Kotani, Organization Kyoto Medical Center, 1-1 Fukakusa mukaihata, Fushimi-ku, Kyoto 612-8555, Japan.

Email: kazukotani@jichi.ac.jp

doi:10.4021/jocmr849w dently, significantly and inversely with the CIMT.

Conclusions: The $\mathrm{Lp}$ (a) levels were inversely correlated with the CIMT in this population, suggesting that subjects with a low $L p(a)$ level may have a predisposition to carotid atherosclerosis. This finding was preliminary and should be investigated further in larger studies and in additional settings.

Keywords: Lp(a); Carotid artery; IMT; Atherosclerosis

\section{Introduction}

Elevated, and particularly extreme, circulating levels of $\mathrm{Lp}$ (a) are considered to be a risk factor for cardiovascular disease (CVD) [1-3]. The dual structure of $L p(a)$, consisting of a cholesterol-laden low-density lipoprotein (LDL) particle and a plasminogen-like glycoprotein apolipoprotein(a), implies that $\mathrm{Lp}$ (a) can contribute to both atherosclerosis and thrombosis [2, 3]. In fact, $\mathrm{Lp}(\mathrm{a})$ has been observed to accumulate in arterial lesions [4]. However, at present, the role of $L p(a)$ in the pathogenesis of atherosclerosis has not been completely elucidated, so the identification of various factors that affect the association of $\mathrm{Lp}(\mathrm{a})$ with atherosclerotic manifestations is necessary.

The sonographic measurement of the thickness of the carotid artery, the carotid intima-media thickness (CIMT), is one of the best accepted surrogate indices reflecting not only local, but also generalized atherosclerosis, associated with cardio- and cerebro-vascular morbidity and mortality, even in asymptomatic individuals [5]. However, the associations observed between the Lp(a) and CIMT have been inconsistent, with several studies having reported positive associations [6-15], while other reported no significant associations [16-24]. There was also a report showing that there was an association between the $\mathrm{Lp}(\mathrm{a})$ and CIMT only in the severe state of the disease [25].

The circulating $L p(a)$ concentrations vary very widely among the populations, and there is generally a skewed distribution, with a high prevalence of the low concentrations [26-28]. In the Japanese population, the distribution of 
Table 1. Clinical Characteristics of Study Subjects

\begin{tabular}{ll}
\hline Variables & Levels \\
\hline Age, years & $60 \pm 10$ \\
Current smoking, $(\%)$ & $9(14 \%)$ \\
Body mass index, $\mathrm{kg} / \mathrm{m}^{2}$ & $23.6 \pm 3.6$ \\
Systolic blood pressure, $\mathrm{mmHg}$ & $135 \pm 19$ \\
Diastolic blood pressure, $\mathrm{mmHg}$ & $78 \pm 9$ \\
Total cholesterol, mg/dL & $261 \pm 38$ \\
HDL-cholesterol, mg/dL & $68 \pm 14$ \\
Triglycerides, mg/dL & $125(92-181)$ \\
Plasma glucose, mg/dL & $107 \pm 22$ \\
Lp(a), mg/dL & $18.6(8.9-24.7)$ \\
CIMT, mm & $0.8 \pm 0.2$
\end{tabular}

HDL: high-density lipoprotein, $L p(a)$ : lipoprotein(a). The values are expressed as the means \pm standard deviation, medians (interquartile range) or numbers.

Lp(a) shows skewing toward the lower concentrations, with most of the population having concentrations $<30 \mathrm{mg} / \mathrm{dL}$, which is considered to be a presumed normal high level of Lp(a) [1]. However, no clinical studies have specifically examined subjects with a low $\mathrm{Lp}$ (a) level. We have noted the implications of a low Lp(a) level in two studies [16, 29]. In those studies, subjects with high CIMT levels were not rarely observed among those with low $\mathrm{Lp}$ (a) levels in one study [16] and the J-curve phenomenon for the incidence of CVD (an increase of the incidence in subjects with the lowest Lp(a) levels) was observed [29]. These findings may be partly related to inconsistent results found for the association between the Lp(a) and CIMT [15-25]. Therefore, the present study was aimed to investigate the correlation between the serum Lp(a) and CIMT in asymptomatic subjects, restricted to those with a low $\mathrm{Lp}(\mathrm{a})$ level.

\section{Methods}

A total of 65 female Japanese subjects were consecutively recruited from our outpatient clinics. Eligible subjects were asymptomatic, non-pregnant and not taking any medications. Only subjects with a serum $\mathrm{Lp}$ (a) level $<30 \mathrm{mg} / \mathrm{dL}$ were included. Subjects who were regular drinkers, and those with a history of CVD, malignancy, endocrine disorders, or severe kidney and liver diseases were excluded. The institutional ethics committee approved the study, and each subject gave informed consent.

Current smoking habits were self-reported. The body mass index (BMI), seated systolic blood pressure (SBP)/diastolic blood pressure (DBP) in the upper arm, and the plasma glucose, serum lipids and $\mathrm{Lp}$ (a) levels were measured after an overnight fast. The glucose and lipids (TC: total cholesterol, HDL-C: high-density lipoprotein cholesterol and TG: triglycerides) were measured enzymatically, and the serum Lp(a) was measured by an ELISA system (Sekisui Medical Co. Ltd., Tokyo, Japan). The CIMT of the common carotid arteries was measured ultrasonographically by a $10 \mathrm{MHz}$ linear type B-mode probe (Xario system: Toshiba Co. Ltd., Tokyo, Japan). The CIMT, bilaterally measured in segments free of plaque (one at the thickest site and another at two other points $(1 \mathrm{~cm}$ upstream and $1 \mathrm{~cm}$ downstream from the thickest site)), was averaged for 3 measurements.

The data are expressed as the means \pm standard deviation or medians plus interquartile range. The correlations between the CIMT and the other variables, including the Lp(a), were examined by Pearson's correlation test, and subsequently, a stepwise multiple linear regression analysis (with $\mathrm{F}$ for the entry set to 2) adjusted for the measured variables (age, smoking, BMI, SBP, DBP, TC, HDL-C, TG, glucose). In these analyses, the TG and $\mathrm{Lp}(\mathrm{a})$ values were calculated after a log-transformation because of their skewed distributions. A P-value $\leq 0.05$ was considered to be significant. 
Table 2. Correlations Between the CIMT and Other Variables, Including the Lp(a), in This Population

\begin{tabular}{|c|c|c|c|c|}
\hline Variables & $\mathbf{r}$ & P-value & $\boldsymbol{\beta}$ & P-value \\
\hline Age, years & 0.33 & $<0.01 *$ & 0.32 & $<0.01 *$ \\
\hline Current smoking, $\mathrm{n}(\%)$ & 0.06 & 0.66 & Not extracted & - \\
\hline Body mass index, $\mathrm{kg} / \mathrm{m}^{2}$ & 0.06 & 0.65 & Not extracted & - \\
\hline Systolic blood pressure, $\mathrm{mmHg}$ & 0.30 & $0.02 *$ & Not extracted & - \\
\hline Diastolic blood pressure, $\mathrm{mmHg}$ & 0.17 & 0.17 & Not extracted & - \\
\hline Total cholesterol, mg/dL & 0.05 & 0.67 & Not extracted & - \\
\hline HDL-cholesterol, mg/dL & -0.12 & 0.33 & Not extracted & - \\
\hline Triglycerides, mg/dL & 0.02 & 0.88 & Not extracted & - \\
\hline Plasma glucose, $\mathrm{mg} / \mathrm{dL}$ & 0.21 & 0.09 & Not extracted & - \\
\hline $\mathrm{Lp}(\mathrm{a}), \mathrm{mg} / \mathrm{dL}$ & -0.24 & $0.05^{*}$ & -0.23 & $0.05 *$ \\
\hline
\end{tabular}

HDL: high-density lipoprotein, $L p(a)$ : lipoprotein(a). $r$ : simple correlation test (Pearson's test), $\beta$ : stepwise multiple linear regression analysis adjusted for all the listed variables. Significance level: * $P \leq 0.05$.

\section{Results}

The clinical characteristics of the study subjects are listed in Table 1. The simple correlations between the CIMT and other variables, including the $\mathrm{Lp}(\mathrm{a})$, are listed in Table 2. There was a significant and positive correlation between the CIMT and subject age or SBP, while a significant and inverse correlation between the CIMT and Lp(a) was observed.

A stepwise multiple linear regression analysis identified subject age to be correlated independently, significantly and positively with the CIMT, and the Lp(a) to be correlated independently, significantly and inversely with the CIMT in this population.

\section{Discussion}

The present study showed that the Lp(a) levels were inversely correlated with the CIMT in asymptomatic female subjects within a $\mathrm{Lp}(\mathrm{a})<30 \mathrm{mg} / \mathrm{dL}$. This suggests that subjects with a low $L p(a)$ level may have a predisposition to carotid atherosclerosis. This study was conducted in a relatively small population, and the correlation was not very strong. However, if the results are confirmed in large studies, the present findings may provide new insights into the physiological roles of $\mathrm{Lp}(\mathrm{a})$ in atherosclerosis.

Of importance, a recent investigation has reported that when $L p(a)$ is present at not so high levels, it can function as a scavenger that absorbs oxidized lipids in the circulation and vessel walls [30]. Accordingly, some minimal level of $\mathrm{Lp}$ (a) may be necessary to protect against atherosclerotic progression, although this concept will need to be verified in additional clinical studies. The circulating $\mathrm{Lp}$ (a) levels are thought to be largely under genetic control (i.e., at the concentration of biosynthesis of the apolipoprotein(a), which is encoded by the LPA locus) [31]. A few studies have been conducted on the significant association among Lp(a) levels, Lp(a)-related gene polymorphisms and atherosclerosis $[32,33]$. Although the evidence of the association of the gene polymorphisms relating to low $L p(a)$ levels in subjects with atherosclerosis remains insufficient, Lp(a) gene polymorphisms and/or its linkage equilibrium may be associated with carotid atherosclerosis. In addition, there was a report that showed a significant interaction of lifestyle factors (i.e., daily fish intake) and $\mathrm{Lp}(\mathrm{a})$-related gene polymorphisms in decreasing the $\mathrm{Lp}(\mathrm{a})$ levels, although one would generally not consider lifestyle factors to have a major influence on the Lp(a) levels [34]. We did not obtain information about the full lifestyle-related factors of the present study subjects, but specific lifestyle-related factors may, at least in part, be associated with the results of the present study, from the previous study findings [34]. Future investigations, taking into consideration genetic and lifestyle factors, may be needed to clarify the biological importance of the results. 
There are additional limitations to our study. The present study was relatively small and cross-sectional. Therefore, we could not conclusively determine the presence of any cause-and-effect relationship based on the results. Furthermore, our study population was asymptomatic and restricted to females and Japanese subjects. Future studies on symptomatic diseased patients and males or other ethnic groups are required.

In summary, this study found that the Lp(a) levels were inversely correlated with the CIMT in asymptomatic female subjects, with a serum Lp(a) level $<30 \mathrm{mg} / \mathrm{dL}$. This suggests that subjects with a low Lp(a) level may have a predisposition to carotid atherosclerosis. This clinical finding should be further investigated in larger studies and additional settings.

\section{Acknowledgement}

This study was supported in part by a Grant-in-Aid for Scientific Research from the Ministry of Education, Culture, Sports, Science, and Technology of Japan (K.K) and the Foundation for the Development of the Community, Japan.

\section{Competing Interests}

The authors declare that they have no competing interests.

\section{References}

1. Murase T, Okubo M, Amemiya-Kudo M, Hiraga T, Oka J, Shimada M, Igarashi T. Impact of markedly elevated serum lipoprotein(a) levels ( $>$ or $=100 \mathrm{mg} / \mathrm{dL}$ ) on the risk of coronary heart disease. Metabolism: clinical and experimental. 2007;56(9):1187-1191.

2. Erqou S, Kaptoge S, Perry PL, Di Angelantonio E, Thompson A, White IR, Marcovina SM, et al. Lipoprotein(a) concentration and the risk of coronary heart disease, stroke, and nonvascular mortality. JAMA : the journal of the American Medical Association. 2009;302(4):412-423.

3. Nordestgaard BG, Chapman MJ, Ray K, Boren J, Andreotti F, Watts GF, Ginsberg H, et al. Lipoprotein(a) as a cardiovascular risk factor: current status. European heart journal. 2010;31(23):2844-2853.

4. Nielsen LB, Gronholdt ML, Schroeder TV, Stender S, Nordestgaard BG. In vivo transfer of lipoprotein(a) into human atherosclerotic carotid arterial intima. Arteriosclerosis, thrombosis, and vascular biology. 1997; 17(5):905-911.

5. Touboul PJ, Labreuche J, Vicaut E, Amarenco P. Carotid intima-media thickness, plaques, and Framingham risk score as independent determinants of stroke risk. Stroke; a journal of cerebral circulation. 2005;36(8):1741-1745.

6. Schreiner PJ, Morrisett JD, Sharrett AR, Patsch W, Tyroler HA, Wu K, Heiss G. Lipoprotein[a] as a risk factor for preclinical atherosclerosis. Arteriosclerosis and thrombosis : a journal of vascular biology / American Heart Association. 1993;13(6):826-833.

7. Schreiner PJ, Heiss G, Tyroler HA, Morrisett JD, Davis $\mathrm{CE}$, Smith R. Race and gender differences in the association of $\mathrm{Lp}(\mathrm{a})$ with carotid artery wall thickness. The Atherosclerosis Risk in Communities (ARIC) Study. Arteriosclerosis, thrombosis, and vascular biology. 1996;16(3):471-478.

8. Rossl A, Baldo-Enzi G, Ganzaroli C, Coscetti G, Calabro A, Baiocchi MR, Maiolino G, et al. Relationship of early carotid artery disease with lipoprotein (a), apolipoprotein B, and fibrinogen in asymptomatic essential hypertensive patients and normotensive subjects. Journal of investigative medicine : the official publication of the American Federation for Clinical Research. 2001;49(6):505-513.

9. Denti L, Marchini L, Pasolini G, Baffoni MT, Ablondi F, Valenti G. Lipoprotein Lp(a) and cerebrovascular disease in the elderly: correlations with the severity of extracranial carotid atherosclerosis assessed by ultrasonography. Acta bio-medica de L'Ateneo parmense : organo della Societa di medicina e scienze naturali di Parma. 1995;66(3-4):175-183.

10. Leinonen ES, Salonen JT, Salonen RM, Koistinen RA, Leinonen PJ, Sarna SS, Taskinen MR. Reduced IGFBP-1 is associated with thickening of the carotid wall in type 2 diabetes. Diabetes care. 2002;25(10):1807-1812.

11. Ohkuma T, Minagawa T, Takada N, Ohno M, Oda H, Ohashi H. C-reactive protein, lipoprotein(a), homocysteine, and male sex contribute to carotid atherosclerosis in peritoneal dialysis patients. American journal of kidney diseases : the official journal of the National Kidney Foundation. 2003;42(2):355-361.

12. Velmurugan K, Deepa R, Ravikumar R, Lawrence JB, Anshoo H, Senthilvelmurugan M, Enas EA, et al. Relationship of lipoprotein(a) with intimal medial thickness of the carotid artery in Type 2 diabetic patients in south India. Diabetic medicine : a journal of the British Diabetic Association. 2003;20(6):455-461.

13. Tsimikas S, Kiechl S, Willeit J, Mayr M, Miller ER, Kronenberg F, Xu Q, et al. Oxidized phospholipids predict the presence and progression of carotid and femoral atherosclerosis and symptomatic cardiovascular disease: five-year prospective results from the Bruneck study. Journal of the American College of Cardiology. 2006;47(11):2219-2228.

14. Linnebank M, Moskau S, Farmand S, Fliessbach K, Kolsch H, Bos M, Grothe C, et al. Homocysteine and carotid intima-media thickness in a german population: 
lack of clinical relevance. Stroke; a journal of cerebral circulation. 2006;37(11):2840-2842.

15. Serban C, Nicola T, Mateescu R, Noveanu L, Susan L, Pacurari A, Caraba A, et al. Serum lipoprotein (a) levels in patients with arterial hypertension. Revista medicochirurgicala a Societatii de Medici si Naturalisti din Iasi. 2010;114(3):798-802.

16. Raitakari OT, Adams MR, Celermajer DS. Effect of $\mathrm{Lp}(\mathrm{a})$ on the early functional and structural changes of atherosclerosis. Arteriosclerosis, thrombosis, and vascular biology. 1999;19(4):990-995.

17. Lavrencic A, Kosmina B, Keber I, Videcnik V, Keber D. Carotid intima-media thickness in young patients with familial hypercholesterolaemia. Heart. 1996;76(4):321325.

18. Stenvinkel P, Heimburger O, Paultre F, Diczfalusy U, Wang T, Berglund L, Jogestrand T. Strong association between malnutrition, inflammation, and atherosclerosis in chronic renal failure. Kidney international. 1999;55(5):1899-1911.

19. Sramek A, Reiber JH, Baak-Pablo R, Sturk A, Rosendaal FR. Lipoprotein(a) and ultrasonographically determined early atherosclerotic changes in the carotid and femoral artery. Journal of thrombosis and haemostasis : JTH. 2003;1(2):374-379.

20. Nasri H, Baradaran A. Association of serum lipoprotein(a) with ultrasonographically determined early atherosclerotic changes in the carotid and femoral arteries in kidney transplanted patients. Transplantation proceedings. 2004;36(9):2683-2686.

21. Brzosko S, Lebkowska U, Malyszko J, Hryszko T, Krauze-Brzosko K, Mysliwiec M. Intima media thickness of common carotid arteries is associated with traditional risk factors and presence of ischaemic heart disease in hemodialysis patients. Physiological research / Academia Scientiarum Bohemoslovaca. 2005;54(5):497504.

22. Grebe MT, Schoene E, Schaefer CA, Boedeker RH, Kemkes-Matthes B, Voss R, Tillmanns HH. Elevated Lipoprotein(a) does not promote early atherosclerotic changes of the carotid arteries in young, healthy adults. Atherosclerosis. 2007;190(1):194-198.

23. El-Gendi SS, Bakeet MY, El-Hamed EA, Ibrahim FK, Ahmed R. The value of lipoprotein (a), homocysteine, and Doppler of carotid and femoral arteries in assessment of atherosclerosis in asymptomatic cardiovascular risk patients. Journal of cardiology. 2008;52(3):202-211.

24. Calmarza P, Trejo JM, Lapresta C, Lopez P. Relationship between lipoprotein(a) concentrations and intima-media thickness: a healthy population study. European journal of cardiovascular prevention and rehabilitation : official journal of the European Society of Cardiology, Working Groups on Epidemiology \& Prevention and Cardiac
Rehabilitation and Exercise Physiology. 2011.

25. Baldassarre D, Tremoli E, Franceschini G, Michelagnoli S, Sirtori CR. Plasma lipoprotein(a) is an independent factor associated with carotid wall thickening in severely but not moderately hypercholesterolemic patients. Stroke; a journal of cerebral circulation. 1996;27(6):1044-1049.

26. Ohtsuki T. Distribution of serum lipoprotein(a) levels--a non-parametric analysis. Hiroshima journal of medical sciences. 1993;42(2):73-81.

27. Bovet P, Rickenbach M, Wietlisbach V, Riesen W, Shamlaye C, Darioli R, Burnand B. Comparison of serum lipoprotein(a) distribution and its correlates among black and white populations. International journal of epidemiology. 1994;23(1):20-27.

28. Marcovina SM, Albers JJ, Wijsman E, Zhang Z, Chapman NH, Kennedy H. Differences in Lp[a] concentrations and apo[a] polymorphs between black and white Americans. Journal of lipid research. 1996;37(12):25692585.

29. Kiechl S, Willeit J, Mayr M, Viehweider B, Oberhollenzer M, Kronenberg F, Wiedermann CJ, et al. Oxidized phospholipids, lipoprotein(a), lipoprotein-associated phospholipase A2 activity, and 10-year cardiovascular outcomes: prospective results from the Bruneck study. Arteriosclerosis, thrombosis, and vascular biology. 2007;27(8):1788-1795.

30. Schneider M, Witztum JL, Young SG, Ludwig EH, Miller ER, Tsimikas S, Curtiss LK, et al. High-level lipoprotein [a] expression in transgenic mice: evidence for oxidized phospholipids in lipoprotein [a] but not in low density lipoproteins. Journal of lipid research. 2005;46(4):769-778.

31. Boerwinkle E, Leffert CC, Lin J, Lackner C, Chiesa G, Hobbs HH. Apolipoprotein(a) gene accounts for greater than $90 \%$ of the variation in plasma lipoprotein(a) concentrations. The Journal of clinical investigation. 1992;90(1):52-60.

32. Clarke R, Peden JF, Hopewell JC, Kyriakou T, Goel A, Heath SC, Parish S, et al. Genetic variants associated with Lp(a) lipoprotein level and coronary disease. The New England journal of medicine. 2009;361(26):25182528.

33. Ronald J, Rajagopalan R, Cerrato F, Nord AS, Hatsukami T, Kohler T, Marcovina S, et al. Genetic variation in LPAL2, LPA, and PLG predicts plasma lipoprotein(a) level and carotid artery disease risk. Stroke; a journal of cerebral circulation. 2011;42(1):2-9.

34. Sofi F, Fatini C, Sticchi E, Lenti M, Gori AM, Giusti B, Fedi $\mathrm{S}$, et al. Fish intake and LPA $93 \mathrm{C}>\mathrm{T}$ polymorphism: gene-environment interaction in modulating lipoprotein (a) concentrations. Atherosclerosis. 2007;195(2):e147154. 